\title{
A Study on Simulating Crowdsourcing Translation in Flipped Classroom
}

\author{
https://doi.org/10.3991/ijet.v12.i08.7143 \\ Zhongwei Mei \\ Luoyang Normal University, Luoyang, China \\ meizhongwei@sina.com
}

\begin{abstract}
As IT dramatically revolutionizes the world; many visionaries have introduced many new pedagogical methodologies and technologies over the years. Present translation teaching was hindered by the teacher-centered mode, while flipped classroom meets the challenges of IT revolution well. Crowdsourcing, as an emerging business mode in the era of internet+, builds up the problem solving strength of the public, is the trend of the times. Likewise, crowdsourcing translation subverts the traditional translation mode. This mode is based on network technologies, translating and proofreading jobs are handed over to volunteers via internet, and the jobs are completed on the wisdom of the masses, which inspires us to try a novel translator training approach. This paper proposes the novel approach to train market-oriented translators via simulating crowdsourcing translation model (CTM) in the "flipped classroom", and analyzes the effects of the effects of the pedagogical reform. The study is of great significance for translator training and online learning.
\end{abstract}

Keywords-Computer-Assisted Simulating, Crowdsourcing Translation, Flipped Classroom

\section{Introduction}

Since the end of 20th century, with the accelerating of global economy, the rapid development of science and technology, the increasing international exchanges and the growing demand for translators and interpreters, the training of qualified translators has been highly stressed. Continuous enrollment enlargement gives impetus to the translation pedagogical reformation and adjustment, which has gained notable achievements. As the core of translator and interpreter cultivation, the undergraduate translation teaching still has enormous problems. Current translation teaching mode can't not keep up with the demand of social development. The translator training mode has to be further reformed. Compound translators should possess many other skills except the requisite language ability. They should master not only the language knowledge of different subjects but master the basic translation techniques as well. Therefore cultivating competence of the critical thinking, problem self-solving, even new technique acquiring is of great significance. But the traditional teaching mode is dated for its lower efficiency. Therefore this paper focuses on flipped-classroom 
teaching mode in simulating crowdsourcing translation, which is a new mode of computer assisted translation with high efficiency.

\section{$2 \quad$ Literature Review}

The traditional translation teaching mode is teacher-centered, which severely limits practical ability expanding and creativity developing, and therefore is bitterly criticized. The rise of flipped classroom (FCR) changes the traditional teaching mode (Jinlei Zhang, Ying Wang, et. 2012). But William J.Z (2016) identifies the need for further research into the FCR. Catherine E. S. (2016) focused on different ways to deliver the same content, and results from his study suggest that a blended type of learning would be optimal and superior, such as learning with a strategic use of video content concepts. Julia E. R (2016) argued that FCR methods can be remedied with a bit of preparation and faculty buy-in, balanced with the proper utilization of technology. Studies show that FCR should be further studied with evidence, and more pedagogical experiment should be carried out based on FCR, so that the efficiency of FLCR could be maximized in teaching.

As for CTM, Anastasiou D. and Gupta R. (2011) compared crowdsourcing translation (CST) with Machine Translation, which proved that the former has its advantages in improving translation quality and efficiency. Omar F. Z., Chris C. B (2011) reported that CST got professional quality from the non-professionals, which is amazing for the quality and efficiency promotion. Lu(Yan Lu 2012) contrasted the characteristics of CST and traditional translation, and discusses the core issues of CST, which implied that the crowdsourcing translation is much better than the traditional translation in that both quality and efficiency could be enhanced. Smith E. and Jönsson M. (2014) argued that crowdsourcing translation mode had been used by several successful organizations to solve their internal Innovation challenges with very good results, especially when the translation task is large in quantity. Based on the crowdsourcing translating practice, Liu(2014) probed into the innovative mechanism and development mode in terms of application of updated translating techniques, project management, work ethics, and team spirits, which are helpful to translator vocational training. Sai (2015) argued that, as a complex adaptive system, unfamiliar people could make collaborative innovation and profit sharing through the Internet by crowdsourcing. He took CST as the research platform, simulated the roles among crowdsourcing platform. This is a forerunning experiment of constructing a convenient simulation environment for the study of crowdsourcing platform.

According to the recent researches, CST is of great significance to expand the translators' practical performance. But so far as we know, no one has applied it in translator training. The author took the lead in experimenting with this new method in FCR for translator training. 


\section{$3 \quad$ Research Design and Data Analysis}

This research aims at analyzing the advantage or disadvantage via simulating CTM in FCR, so as to improve the translation teaching. Simultaneously, with an objective of testing the effects of FLC in teaching computer assisted translation. According to this, we take the researches as follows.

\subsection{Research Method}

This research is carried out in Luoyang Institute of Science and Technology with the help of lecturer Ms. Zhang Lin. The course of the research is co-designed by the author and Ms. Zhang Lin, while the course of the teaching is carried out by Ms. Zhang, who provided with many detailed data. In order to make the research more objective, the analysis is done based on the data by the author independently.

In order to make the students understand the course aim and get familiar with the application of CAT tools such as iCAT, Trados, etc., we adopted the concept of a FCR to extend courses beyond classrooms through online videos and concrete operation manuals. We provide translation trainees with an autonomous learning environment for improving the training effects. And the FCR is integrated into a translation course, with the midterm as the transition point between the traditional teaching method and the FCR method. By comparing the learning effects of the two teaching methods, the students' active learning was observed and recorded. Questionnaires were administered at the beginning, middle, and end of the semester to determine the students' perceptions of a flipped translation classroom. We take exercise performance and test score as the main data for analyzing. The subjects of this study were 30 students in 2 translation course-classes.

During the semester, the students were assigned to translate texts from different subject realms, such as engineering and technology. These texts were selected by the students at the beginning of the semester and approved by the teacher on the basis of text difficulty. After learning the translation technology and strategies, exercises related to the practice were conducted to strengthen students' learning effects.

As the flipped class model, there are three major steps: (1) The pre-class arrangements with videos and related reading materials according to the students' backgrounds and ideas; (2) The in-class organization for securing the success of the whole classes; (3) The after-class assessment and consolidation of the in-class contents. The students' feedbacks and assessments are very important for the class effects. Figure 1 shows how the pedagogical theory was practiced in an interactive process, which included various midcourse corrections in response to ongoing suggestions from each test subjects with details.

\subsection{Pre-class Arrangements}

The specialty of translation aims at cultivating professional translating talents who are well developed morally, intellectually, physically and aesthetically. Students of this specialty will be equipped with full competence of literary taste, good vocational 
morality, strong bilingual ability, ability in intercultural communicating, translating and interpreting, thinking and creating, so that students of this specialty will be qualified for different jobs of translation in the field of foreign affairs, business, culture, technology, etc. with international horizon. According the above requirements, the course of Computer Assisted Translation is arranged as follows.

The one-semester-long course is divided into 10 weekly topics, consisting of assigned readings with 3 or 4 video lessons that each averagely lasts about 8 or 9 minutes. The videos remain permanently accessible on web, and a deadline to earn participation points insures completion before the in-class exercises. As the first half of the "FCR", these lessons are extremely popular with students, particularly for the flexibility to complete assignments for the students' convenience, to pause the videos and take notes as needed, rewind and rewatch portions if unclear on any concepts, and to later access portions of the lessons for homework and exam reviews. Those students already familiar with specific topics appreciate the option to work ahead without being required to sit through unnecessary lectures.

Each of the 3 or 4 weekly video lessons concludes with a short online quiz, consisting of 2 to 4 questions designed to record students' participation and gauge their degree comprehension. Students are required to answer all the questions correctly before moving on to the next video - they are sequentially staged - and may answer the questions as many times as it takes possibly. The object of the quizzes is to demonstrate progressive mastery through immediate feedback, not grading. Ideally, more challenging, open-ended questions and spreadsheet calculations would allow students to do it more fully, which demonstrates the incremental mastery, but the U of MN's online Model Learning Management System (LMS) cannot accommodate such questions in a progressive, auto-graded format.

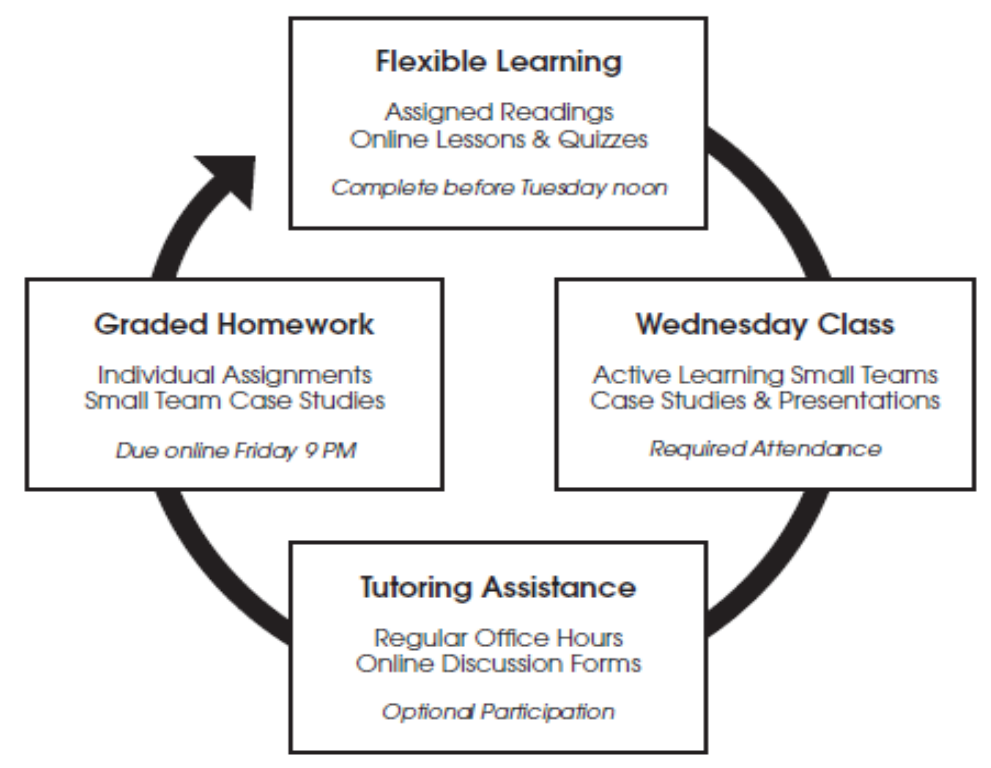

Fig. 1. Flipped Classroom Weekly Cycle 


\subsection{In-class Organization}

Class time is dedicated to active learning sessions, which allow direct interaction with the instructors as students apply the video lessons by solving practical cases in small team settings. Mini-reviews of the week's material introduce the ungraded exercises, and all teams submit their work online. Correspondingly, they will receive participation points according to their performance. The session concludes with students' presentations of their solutions, accompanied by brief interactive discussions to reinforce the lessons.

As the second half of the FCR, these sessions are also extremely popular, since instructors are available when needed-while students are actually doing their homework. Randomly, tasks are assigned to 2 or 3-person teams, which encourages active participation. In this model, the students are required to accept responsibility for completing the preparatory lessons on time. They are allowed to do their productive participation in the team learning activities, and not simply show up to absorb a lecture or freeload on their classmates who did complete the assigned background material. Peer pressure and credit for timely completion effectively reinforces this real-world expectation, where any failure to meet assigned deadlines can compromise the performance of other team members and the overall organization, which is just like the mode of crowdsourcing translation in big translation corporations.

Tutoring assistance is focused on the period between the in-class ungraded work and graded homework submission. Regular office hours immediately follow the sessions for those who need additional explanations, and the instructor is also available for those who need help on the graded assignments. In addition, an online discussion forum allows students to post questions on graded assignments for the instructor to answer, all of which is available for any student to review. Besides, for the convenience of the students, some new media are also used to help the students, such as WeChat, email, etc.

Pretest results, as is shown in table 1, revealed that more than half of the students believed that a translation class should be student-centered at the beginning of the semester: In addition, $95 \%$ of the students valued the importance of in-class participation and homework assignments (ICP\&HS) in a translation class. Although none of the students considered a lecture effective for achieving the optimal learning effects at the beginning of the semester, most of the students expected to learn through individual study, followed by translation homework, group study, and finally in-class translation activities.

Table 1. Pretest results on the students attitudes

\begin{tabular}{|c|c|c|}
\hline datum type attitudes & student-centered & ICP\&HS is important \\
\hline Number & 34 & 57 \\
\hline Percentage & $57 \%$ & $95 \%$ \\
\hline
\end{tabular}

FCR has transformed the teacher-centered translation classroom into a studentcentered one. On the contrary, teachers have to learn with students and consider their 
needs, interests, abilities, and weaknesses during curriculum design, whereas in the former model, students passively accept assigned tasks, their needs and other factors are not taken into consideration for an autonomous learning environment, which neglect and stifle the student's creativity.

A questionnaire was administered at the middle of the semester, as shown in figure 2. After 8 weeks of the flipped translation class, the students were asked whether they had previewed the lessons beforehand in their three assignments. For the first assignment, $83 \%$ of the students had previewed the lessons. Those who had not previewed the lesson attributed the cause to forgetfulness or something special else. In the second assignment, almost all the students had previewed the lesson. However, in the third assignment, $90 \%$ of students had previewed the lesson but $10 \%$ had forgotten.

The students were asked to rank from 1 to 5 whether previewing the lessons helped their learning effects, with 5 being most helpful; the average was 4.45 , indicating that most of the students were positive in previewing the lessons. During class, simulating CTM with SDL Trados Studio was assigned to the students. The students considered the in-class assignments extremely helpful to their learning, much more helpful than previewing the video tutorial and operation manuals, as is shown in figure 3.

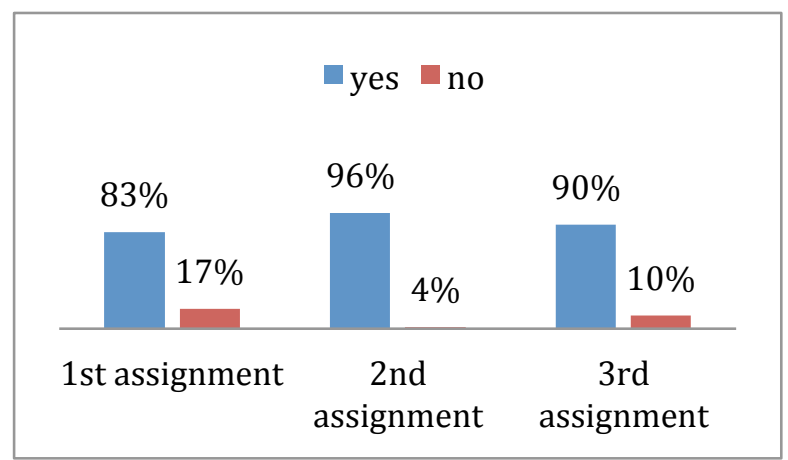

Fig. 2. Preview Percentage

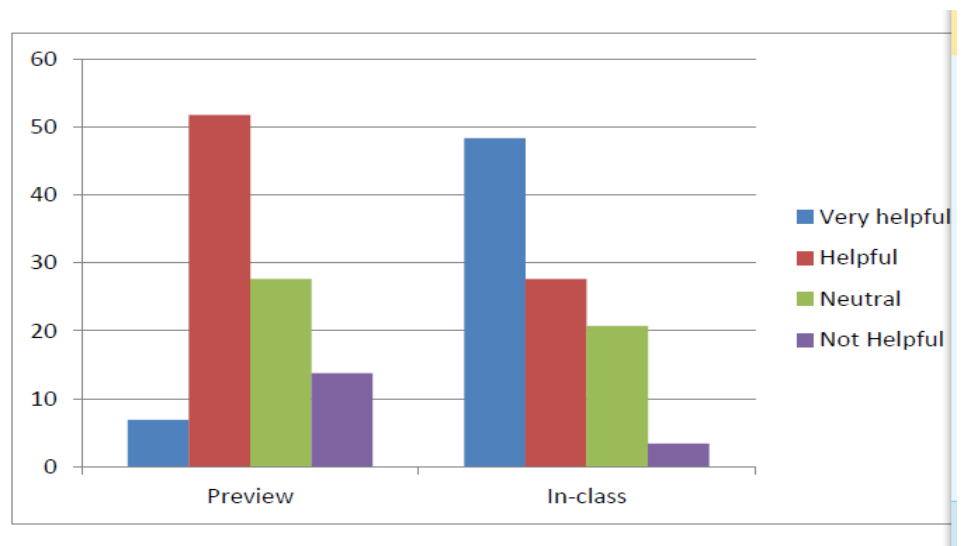

Fig. 3. Attitude Change 
One additional questionnaire was administered in the final (8th) week of the traditional teaching method, the students were again asked to rank the activities according to how much they believed they learned from them, as is shown in figure 4 . The posttest results were distinct from the pretest results. It is determined that the preference for individual study at the beginning of the semester was least supported at the end of the semester. In-class translation activities, which were not favored at the beginning of the semester, eventually were highly valued at the end of the semester; group study yielded similar responses to the former. This indicates that the students encountered the effects of in-class translation activities and group study in their learning, and that translation was learned more effectively by simulating crowdsourcing translation model and interacting with classmates and teacher.

The data and analysis above is about the subjective attitude change, which proves that the students welcome the new pedagogical model in that it boosts the activity and enhances the ability of them in translation technique learning. In other words, simulating crowdsourcing translation in a flipped classroom turns out to be popular with the translation trainees. Generally speaking, the pedagogical innovation is a successful experiment, which should be explored further and wider.

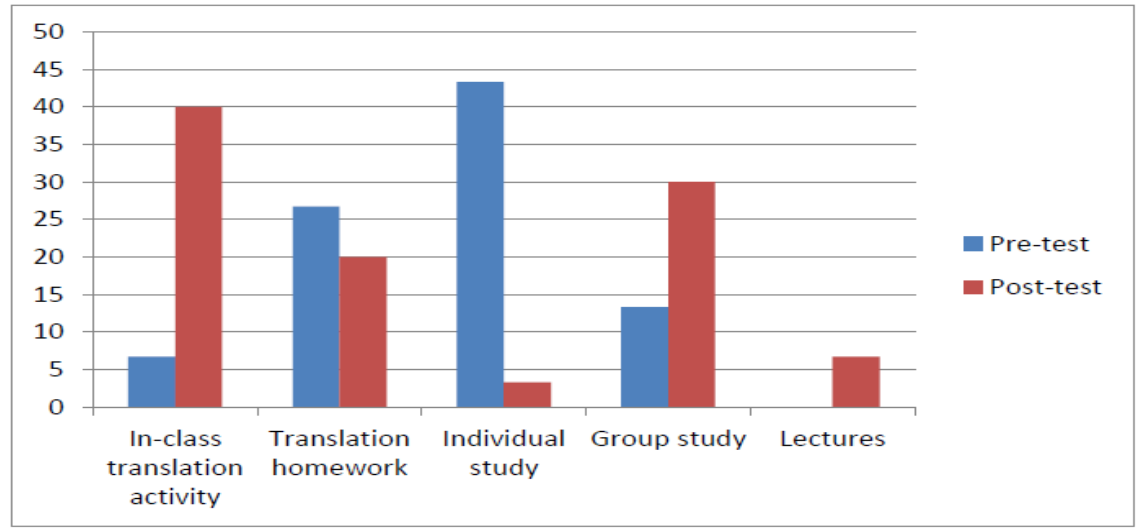

Fig. 4. Effective of Experiment

\subsection{After-class Assessment}

After the class, the students are organized to talk about their learning, no matter criticizing or praising. The students are satisfied with the experiences of finding some comments before class, and try to translate some sentences afterwards. They share their leaning funs before class and are glad to perform in class. They are looking forward to having more CTM practices.

For students to understand the course and become familiar with the application of CAT tools, we adopted the concept of a FCR to extend courses beyond classrooms through online videos and annotations. We aimed to provide student translators with an autonomous learning environment and to improve translation training efficiency. 
We integrated the FCR into a computer-assisted translation course, with the midterm as the transition point between the traditional teaching method and the FCR method. By comparing the learning effects of the two teaching methods, the students' activities of learning was observed. Questionnaires were administered at the beginning, middle, and end of the semester to determine the students' perceptions of a flipped translation classroom. Related data have been used in former analysis and that as follows.

\subsection{Effects of Simulating CTM in FCR}

Ability of self-solve problems and some critical things. In a crowdsourcing process, we may distinguish three different general phases separated roughly by the start and end of the crowdsourcing challenge. In the pre-challenge phase, the focus is mainly on the problem definition, carried out in the seeker s' context. During the challenge, the focus changes to the solvers' working to create winning solutions, in virtual environments shared between seekers and solvers. After the challenge ends, the focus is on the evaluation, selection and learning of the winning solutions carried out in the seeker's context. The pre-challenge phase starts with the acknowledgement of an existing problem and ends with a written explanation of the problem at hand. The challenge, or the "solution creation" phase, starts with the written description of the problem and ends with an explicit description of possible solutions to this problem. The post challenge or "solution learning" phase starts with explicit descriptions of solution for the problem and ends when the selected solutions are incorporated into the seeker's knowledge base. Abstracting from the complexity of these phases, each of them represents, basically, a knowledge conversion mode, namely: the "problem creation" phase converts tacit information into explicit knowledge and therefore is essentially an externalization phase, the "solution creation" phase is, in the seeker perspective, a combination phase. Since explicit knowledge is converted into new explicit knowledge and the "solution learning" phase is basically an internalization phase. Since new tacit knowledge is created from the explicit knowledge. The generic view of the Crowdsourcing process as a sequence of knowledge conversion modes, which is illustrated in Figure 5.

This generic conceptualization of the crowdsourcing process clearly illustrates that the tasks preceding and preceded by the Crowdsourcing challenge are of vital importance for the success of the Crowdsourcing initiative. Nevertheless, the novelty in Crowdsourcing is the ability to explore solutions for organizational problems, developed by unknown external knowledge, during the Crowdsourcing challenge. In order to understand more profoundly the Crowdsourcing process, Figure 5 illustrates a detailed conceptualization of Crowdsourcing seen through the lenses of the theory of organizational knowledge creation. This conceptualization results from a deductive exercise based on the theory and on the description of several Crowdsourcing Innovation initiatives presented on the literature. 


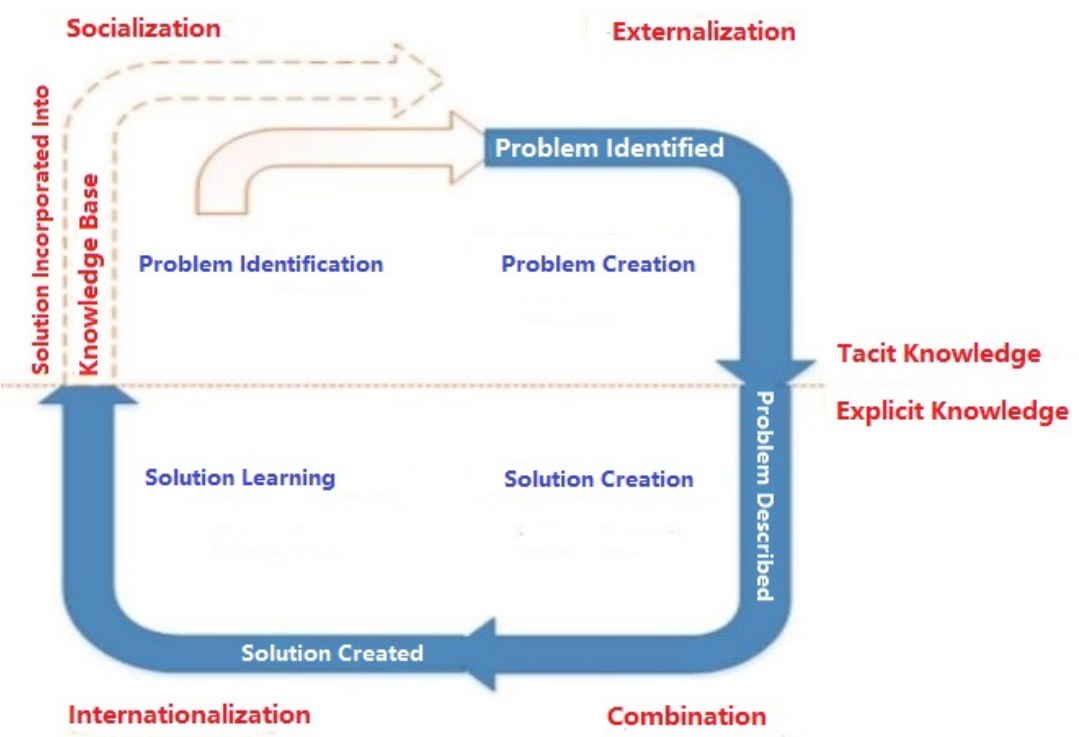

Fig. 5. Crowdsourcing Process

Improvements in Student Engagement.Although monitoring and modification obviously is badly needed to continue, initial results in the two terms of the 2014 2015 academic year were very encouraging. Perhaps the most important, students' engagement was significantly higher than with the traditional model comparatively. Course evaluation surveys historically document that few students read the assigned chapters - regardless of the teaching methodology. The students' engagement can be determined by two variables. Firstly, the completion rates for learning tasks or quizzes; Secondly, the participation rates for learning (as is shown in figure 6). In contrast, completion rates for the videos/quizzes averaged more than $99 \%$, considerably better than the lecture capture rates $91 \%$ on my most scintillating of days. As an even more telling measure, participation rates on in-class small team Ungraded Assignments (UA) averaged 96\%, compared with 91\% under the traditional lecture-focused(TLF) model (previous four-term average), despite the same requirement that homework could only be submitted during class to receive credit. Significantly, attendance with the FCR model remained high throughout the semester, unlike in previous terms when attendance lagged during the latter weeks. This consistently higher attendance level throughout the term likely reflects the greater perceived value of the FCR. 


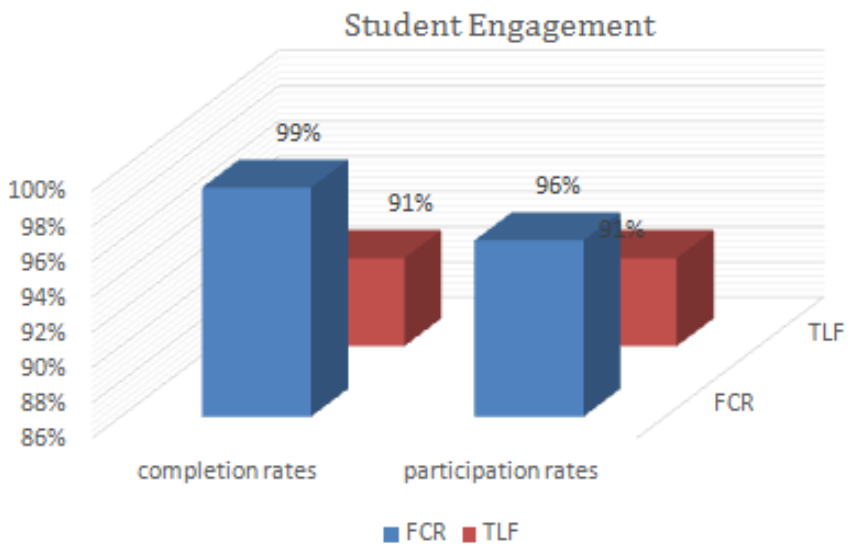

Fig. 6. Data on Student Engagement

With background videos completed ahead of time, and in-person attendance only required one day a week, students know their class time will be well spent. Feedback on the student online discussion forum provides a clear explanation for such a high level of student engagement - and a compelling endorsement of the new model. Some students were generally not as comfortable with the greater flexibility, since it required them to take responsibility for doing the outside work in a timely way and not merely show up in class to passively absorb the material through lectures. Neither does this learning model reward those students who tend to rely on their generic oratory skills to sail through classes; they are required to work with others and actually complete the assignments.

Improvements in Student Mastery. Although periodic modifications in general exam structures and specific test questions complicate term-to-term comparisons, student mastery of similar material was measurably better under the FCR model than with traditional lecture-focused(TLF) instruction. Scores on individually graded exercises averaged $93 \%$ with the FCR, compared with $86 \%$ over the four previous terms, as adjusted for the new, more difficult, all-spreadsheet format. GA's in previous years included definitional questions that were routinely all answered correctly; these are now included in the ungraded online quizzes. Graded assignment scores were significantly higher when FCR had access to a technology-friendly Active Learning Classroom in the spring of 2015. Comparative results on the two team case studies documented similar greater mastery under the FCR model. Tests show the scores for both case studies combined averaged $96 \%$ under the new instructional method, compared with $92 \%$ over the two most recent terms in which these tests were carried. The scores were generally comparable, due primarily to one prior traditional class, which boasted a particularly high average. Otherwise, exam scores were slightly higher with the FCR method. Interestingly, the exceptional previous class had much lower scores on individually graded GA assignments.

These demonstrated improvements affirm a fundamental premise of the FCR model. Traditional exams, which test rote knowledge on time-limited, resource-restricted 
tests, are arguably less predictive of real-world success, because they do not mirror the actual requirements of the working world. Consequently, teaching to the test has less relevance in a course designed to equip students with such practical skills as accepting responsibility for independent learning and collaboratively solving real-life challenges. The significant improvements in individual Graded Assignments and team Case Studies are far more appropriate measures. These results are a particularly meaningful endorsement of the new learning model.

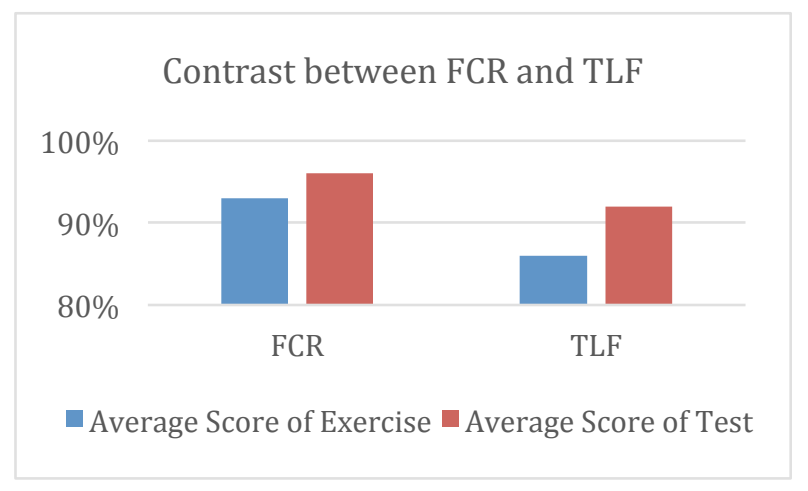

Fig. 7. Comparative Results on the 2 Modes

\section{Conclusion}

With the experiences of flipped classroom model, Crowdsourcing translation mode is integrated into the translator training class. Generally speaking, the translation course reform is successful. Facts and data prove that the new method is efficient in the classroom translation teaching. On the one hand, the students are active in learning with the new technological method, which helps the students to learn by themselves before class. On the other hand, this method saves a lot of in-class time, and the students have more time to practice with the classmates to share their learning experience with the peers. And more importantly, the new method not only improves the teaching and learning efficiency, but also make the students more creative and innovative. In the era of internet, the learning resources are more accessible for the students and any learners. In the long run, the flipped class can be the prior period for the flipped learning, which will be widely used in the fragmented learning, Internet learning, etc.

\section{$5 \quad$ References}

[1] Anastasiou, D., Gupta, R. (2011). Comparison of crowdsourcing translation with Machine Translation, Journal of Information Science, 8(6), 637-659. https://doi.org/10.1177/ $\underline{0165551511418760}$ 
Paper-A Study on Simulating Crowdsourcing Translation in Flipped Classroom

[2] Catherine, E.S., Linda, E.G., Debra, L.E. (2016). A comparison between flipped and lecture-based instruction in the calculus classroom, Journal of Applied Research in Higher Education, 11(2), 252-264.

[3] Zhang, J.L., Wang, Y., Zhang, B.H. (2012). Introducing a New Teaching Model: Flipped Classroom, Journal of Distance Education, 5(4), 46-51.

[4] Julia, E.R. (2016). A massively flipped class: Designing and implementing active learning information literacy instruction for a large enrollment course, Reference Services Review, 12(1), 4-8.

[5] Lage, M. J., Platt, G.J., Treglia, M. (2000). Inverting the classroom: A gateway to creating an inclusive learning environment. The Journal of Economic Education, 31(1), 30-43. https://doi.org/10.1080/00220480009596759

[6] Omar, F.Z., Chris, C.B. (2011). Crowdsourcing Translation: Professional Quality from Non-Professionals, Conference on European Chapter of the Association for Computational Linguistics (EACL 2011), pp.1-5.

[7] Lv, S. (2015). Modeling and Simulating of Crowdsourcing Translation Platform Based on Complex Adaptive System, Computer System Application, 16(2), 7-13.

[8] Smith, E., Jönsson, M. (2014). Crowdsourcing: A Tool For Organizational Knowledge Creation, Twenty Second European Conference on Information Systems, Tel Aviv 2014, pp.1-10.

[9] Wang, Z.L. (2015). The fragments and reconstruction, Beijing: Publishing House of Electronics Industry, pp.37-40.

[10] William, J.Z. (2016). The flipped classroom, a review of the literature, Industrial and Commercial Training, 48(2), pp.97 - 103 https://doi.org/10.1108/ICT-05-2015-0039

[11] Lu, Y. (2012). Research on Crowdsourcing Translation, Shanghai Journal of Translators, 16(3), 74-78.

[12] Zhang, L. (2016). Study on the Application of Web Information Retrieval in the Teaching of Language Translation, International Journal of Emerging Technologies in Learning, 11(04), pp. 114-119. https://doi.org/10.3991/ijet.v11i04.5550

[13] Zhang, E.W., Zhang, W.M. (2013). Application of Computer-Aided Translation Technology in Translation Teaching. International Journal of Emerging Technologies in Learning, 8(5), pp.120-128

[14] Jiang, J.L., Qin, Y., Sun, Y. (2016), Constructing Automated Scoring Model for Human Translation with Multidisciplinary Technologies, International Journal of Emerging Technologies in Learning, 11(2), pp.74-80 https://doi.org/10.3991/ijet.v11i02.5137

[15] Matthias, T., Benjamin, W., Birgit, R.I., Duc, B.Vu., Fuchs, M., Matthias L.H. (2016). Innovative Authoring Tools for Online-Courses with Assignments - Integrating Heterogeneous Tools of e-Learning Platforms into Hybrid Application Solutions, International Journal of Emerging Technologies in Learning, 11(2), pp. 36-42

\section{Author}

Zhongwei Mei is a lecturer in the School of Foreign Languages, Luoyang Normal University, Luoyang, 471023, China. He is also a Ph.D. of applied linguistics in Central China Normal University, and his research interests include Translation, Computational Linguistics, etc.

Article submitted 08 May 2017. Published as resubmitted by the author 14 June 2017. 